\title{
Criação e reprodução no ensino de artes visuais: análise de paradigmas teórico- metodológicos
}

\author{
Creación y reproducción em la enseñanza \\ de las artes visuales: análisis de \\ paradigmas teóricos y metodológicos.
}

\section{Vinícius Stein ${ }^{1}$ \\ Marta Chaves ${ }^{2}$}

\footnotetext{
1 Graduação em Arte-Educação pela Universidade Estadual do Centro-Oeste 2011). Especialização em Teoria Histórico-Cultural pelo departamento de Psicologia da Universidade Estadual de Maringá (2014). Mestrado em Educação pelo Programa de Pós-Graduação em Educação da Universidade Estadual de Maringá (2014). Doutorado em Educação pelo Programa de Pós-Graduação em Educação da Universidade Estadual de Maringá (2019). Recebeu bolsa da Fundación Carolina para pesquisa na Universidad de Huelva - Espanha (2018). É coordenador do Conselho Acadêmico do curso de licenciatura em Artes Visuais da Universidade Estadual de Maringá (2019). Integra o Grupo de Pesquisa e Estudos em Educação Infantil (GEEI) e o Grupo de Pesquisa em Arte, Educação e Imagem (ARTEI). Pesquisa sobre ensino das artes visuais na educação escolar e sobre educação estética.

Currículo Lattes: http://lattes.cnpq.br/2140194065685423
}

${ }^{2}$ Graduação em Pedagogia pela Universidade Estadual de Maringá (1993). Mestrado em Educação pela Universidade Estadual de Maringá (2000). Doutorado em Educação pela Universidade Federal do Paraná (2008). Pós-Doutorado junto ao Departamento de Psicologia da Educação, na Faculdade de Ciências e Letras do Campus de Araraquara - Unesp (2011). É professora associada do Departamento de Teoria e Prática da Educação da Universidade Estadual de Maringá e líder do Grupo de Pesquisa e Estudos em Educação Infantil (GEEI). Tem experiência na área de Educação, com ênfase em História da Educação, atuando principalmente nos seguintes temas: Formação de professores, Educação Infantil, Teoria Histórico-Cultural, Literatura Infantil, Arte e Intervenções Pedagógicas.

Currículo Lattes: http://lattes.cnpq.br/3623759765067532 


\section{Resumo}

O texto apresenta o resultado de uma pesquisa teórica, com delineamento bibliográfico, cujo objetivo foi analisar as concepções sobre os processos de criação vinculados a dois paradigmas teórico-metodológicos consolidados para o ensino de artes visuais: a mimese e a autoexpressão. Expõe aspectos históricos que propiciaram o desenvolvimento de ambos os paradigmas. Expressa os limites e potencialidades das abordagens mediante análise em uma lógica dialética. Conclui que desenvolver processos de criação em artes visuais na Educação Básica implica possibilitar a apropriação de conhecimentos e habilidades desenvolvidos historicamente, pois a reprodução, no âmbito individual, daquilo que fora criado e é compartilhado socialmente, representa a formação da base que possibilitará o desenvolvimento de novas criações.

\section{Palavras-chave}

Arte; Mimese; Autoexpressão; Educação Básica; Teoria Histórico-Cultural;

\section{Resumen}

El texto presenta el resultado de una investigación teórica, con un diseño bibliográfico, cuyo objetivo fue analizar las concepciones sobre los procesos de creación vinculados a dos consolidados paradigmas teórico-metodológicos para la enseñanza de las artes visuales: la mimesis y la autoexpresión. Expone aspectos históricos que favorecieron el desarrollo de ambos paradigmas. Expresa los límites y el potencial de los enfoques a través del análisis en una lógica dialéctica. Concluye que desarrollar los procesos de creación en artes visuales en la Educación Básica implica permitir la apropiación de los conocimientos y habilidades desarrolladas históricamente, ya que la reproducción, en el ámbito individual, de lo que se ha creado y se comparte socialmente, representa la formación de la base de que permitirá el desarrollo de nuevas creaciones.

\section{Palabras-clave}

Arte; Mimese; Autoexpresión; Educación básica; Teoría histórico-cultural; 


\section{Considerações iniciais}

O ensino das artes visuais vem sendo realizado ao longo do tempo por meio de diferentes metodologias. A variedade metodológica para o ensino pode ser relacionada às diferentes concepções relativas aos processos de criação artística, pois na medida em que os modos de produzir arte foram alterados, as maneiras de ensinálos também passaram por modificações. Se "toda obra de arte é filha de seu tempo [...]", como propôs Wassily Kandinsky (1996, p.27), em Do espiritual na arte e na pintura em particular, para nós, toda iniciativa de arte educação também o é.

Nessa direção, conforme explicaram Maria Heloísa Corrêa de Toledo Ferraz e Maria Felisminda de Rezende Fusari (2010), em Arte na educação escolar, o ensino de artes visuais foi marcado pelas diferentes linhas pedagógicas e ideológicas atribuídas à arte ao longo da história e, em nossa avaliação, ainda hoje contribuem para as decisões tomadas pelos professores na organização e planejamento de suas ações pedagógicas com artes visuais na Educação Básica1.

Diante disso, realizamos uma pesquisa teórica, com delineamento bibliográfico (GIL, 2002), cujo objetivo foi analisar as concepções sobre os processos de criação vinculados a dois paradigmas teórico-metodológicos consolidados para o ensino de artes visuais: a mimese e a autoexpressão. As seguintes perguntas motivaram nossa investigação: Quais as concepções de criação implícitas nesses dois paradigmas para o ensino de artes visuais? Que alternativas metodológicas para ações de arte educação eles sugerem? Quais os seus limites e as suas potencialidades?

Esses questionamentos remetem aos fundamentos teórico-metodológicos para o desenvolvimento da criação, temática que estudamos junto ao Grupo de Pesquisa e Estudos em Educação Infantil - GEEl ${ }^{2}$ e que fora contemplada em Formação artística e estética de professores e crianças: desenvolvimento da criação com artes visuais na Educação Infantil (STEIN, 2019).

Diante disso, na primeira parte deste texto, apresentamos o paradigma da mimese, recuperando os aspectos históricos que propiciaram o seu desenvolvimento. $\mathrm{Na}$ segunda parte, realizamos exercício semelhante, tratando sobre o paradigma da autoexpressão. Na terceira, analisamos ambos e, em seguida, apresentamos nossas considerações finais.

\footnotetext{
${ }^{1}$ Segundo a Lei que estabelece as Diretrizes e Bases da Educação Nacional (BRASIL, 1996), a educação escolar no país compõe-se de: I - Educação Básica, formada pela Educação Infantil, Ensino Fundamental e Ensino Médio; e II - Educação Superior (Art. 21). A Educação Infantil é realizada em creches e pré-escolas, com crianças de até cinco anos de idade (Art. 29). O Ensino Fundamental tem duração de nove anos, iniciando-se aos seis anos de idade (Art. 32) e, por fim, o Ensino Médio, possui duração mínima de três anos (Art. 35). O ensino da arte é garantido como componente curricular obrigatório em todas as etapas da Educação Básica (Cf. §2 Art. 26).

${ }^{2}$ Coordenado pela Dra. Marta Chaves, o GEEl é formado por estudantes e docentes da Universidade Estadual de Maringá-PR e também por pesquisadores de Instituições de Ensino Superior do Paraná, Rondônia e São Paulo. Os objetivos do grupo são: pesquisar e socializar estudos afetos à formação dos profissionais que atuam com crianças, bem como investigar práticas pedagógicas realizadas nas instituições de Educação Infantil. (DIRETÓRIO..., 2020).
} 


\section{O paradigma da mimese: a reprodução como criação}

A mimese (ou imitação), como meio para o ensino, foi realizada desde a gênese da arte $^{3}$. Como exemplo disso, mencionamos Dulce Regina Baggio Osinski (2010), em Arte, história e ensino, onde afirmou que a refinada e elaborada técnica utilizada nas pinturas produzidas no período Paleolítico sugere o desenvolvimento de um processo informal de ensino baseado na imitação daqueles que "[...] transmitiam o conhecimento através do exemplo de seu próprio fazer" (OSINSKI, 2010, p.14).

Na filosofia da arte, desde a Antiguidade Clássica, as discussões acerca da mimese permearam os debates relacionados à definição da arte e, embora a compreensão sobre a relevância da imitação na produção artística tenha sido transformada pelas diferentes reflexões filosóficas ao longo do tempo, como demonstrou Marcos Henrique Camargo (2009), no artigo As estéticas e suas definições da arte, ainda hoje, permanecem as relações entre arte e imitação tanto nos debates acadêmicos, quanto no senso comum. Essas relações também foram evidenciadas por Vera Lúcia Penzo Fernandes (2010), em A imitação no processo de ensino e aprendizagem de arte.

O uso da observação e da imitação como meios de ensino, aprendizagem e criação artística permitiu o desenvolvimento de funções psicológicas humanas cada vez mais complexas. Esse processo, vinculado ao desenvolvimento da produção material, propiciou a especialização e divisão do trabalho e a separação dos indivíduos em duas classes sociais (a dos proprietários e a dos não-proprietários) e, por extensão, provocou uma divisão também na educação. Conforme explicou Demerval Saviani (2007), em Trabalho e educação: fundamentos ontológicos e históricos, essa divisão foi definida da seguinte forma: "uma para a classe proprietária, identificada como a educação dos homens livres, e outra para a classe não proprietária, identificada como a educação dos escravos e serviçais" (SAVIANI, 2007, p. 155). Essa relação pode ser percebida, por exemplo, na organização social no Egito e, de modo mais acentuado, nas sociedades orientadas pela cultura greco-romana, como relatou Arnold Hauser (1994) em História social da arte e da literatura. Conforme explicou o autor, ainda que os gregos tenham organizado espaços específicos para a formação intelectual, a escultura e a pintura, por exemplo, mantiveram-se apartadas do sistema educativo organizado, sendo ensinadas nas oficinas artesanais.

Ao avançarmos os séculos notamos a permanência dessa forma de ensino em outros contextos. Segundo Osinski (1998; 2001), durante a Idade Média, a hegemonia da igreja católica sobre as demais instituições sociais contribuiu para que a arte e a literatura fossem colocadas a seu serviço. Os mosteiros se constituíam centros de intensa produção, desenvolvendo atividades de cópia e criação de iluminuras nos livros, na arquitetura e também na escultura, pintura, ourivesaria, esmaltagem, tecelagem, tapeçaria, encadernação e cerâmica.

\footnotetext{
3 Cabe destacar, em acordo com Lucia Santaella (2005, p. 5), que "no mundo antigo e na Idade Média, o que hoje chamamos de artes visuais era considerado como artesanato utilitário dentro do mesmo paradigma de outros tipos de artesanato [...]". Assim, nos referimos às produções da antiguidade e medievo como artes visuais, ainda que elas não fossem reconhecidas dessa maneira no momento em que foram produzidas.
} 
A afirmação do poder da igreja católica motivou a construção de grandes catedrais que representavam a sua superioridade. Para atender a essa finalidade, entre os séculos XII e XIII, foram criadas cooperativas de artistas, as quais foram chamadas de lojas dos pedreiros. A organização rígida das lojas mantinha os "[...] ajudantes subordinados aos aprendizes, os quais recebiam ordens dos mestres das diferentes modalidades de artesanato, vindo esses a se submeterem ao mestre de construção" (OSINSKI, 1998, p.21).

Ainda segundo a autora, nas lojas, diferentes especializações artísticas eram realizadas. Com o tempo, seus artesãos começaram a se estabelecer como mestres independentes em função do desenvolvimento da burguesia urbana. O poder de compra dos burgueses motivou o desenvolvimento de um mercado para o consumo de arte. Esse processo foi intensificado por volta do século XIV, quando os artistas, para protegerem seu mercado e restringirem a concorrência, organizaram o sistema de corporações ou guildas.

Nessa concepção, para aprender um ofício era necessário começar a trabalhar como ajudante de um profissional reconhecido em determinada área, conforme descreveu Ricardo Marín Viadel (1997), em Enseñanza y aprendizaje en Bellas Artes: una revisión de los cuatro modelos históricos desde la perspectiva contemporánea. O processo de aprendizagem era gradativo e, de início, contemplavam as atividades mais simples. No caso da aprendizagem de pintura em tela, por exemplo, segundo o autor, o aprendiz começaria "[...] preparando e limpando os instrumentos e materiais, aprendendo como se chama cada coisa, quando se utiliza isto ou aquilo, [e] para que serve cada elemento [...]" (VIADEL, 1997, p. 58). Assim, gradualmente eram realizadas tarefas complexas e que exigiam maiores responsabilidades. Após anos de experiência, o ajudante teria compartilhado da maioria dos problemas enfrentados por seu mestre e seria, por hipótese, capaz de resolvê-los por conta própria, podendo realizar aquele ofício de modo independente.

Até esse momento histórico, a experiência e a prática serviram como modelo principal para a aprendizagem das artes visuais, porém, as mudanças estruturais da organização social provocaram alterações significativas no modelo de ensinar as artes.

Conforme explicou Saviani (2207) o desenvolvimento das forças produtivas intensificou a economia medieval e promoveu a geração de recursos excedentes. As trocas entre produtos excedentes motivaram o desenvolvimento do comércio e a organização da produção visando o estímulo das trocas que, por sua vez, permitiu a acumulação de propriedade privada e deu origem à sociedade capitalista.

O movimento artístico que acompanhou as transformações na organização econômica e social à época ficou conhecido como Renascimento. Iniciado na Itália por volta do século XVI, esse movimento expressou as mudanças da sociedade europeia. Sobre ele Osinski (1998, p.25) destacou:

[...] O homem, afastando-se progressivamente dos dogmas religiosos, descobriu o mundo e colocou-se no centro das preocupações investigativas. O naturalismo, manifestado anteriormente em outros períodos da história da arte, assumiu então o caráter científico e metodológico e passou a dominar 
a expressão artística, a qual se converteu no estudo da natureza. O objetivo do artista limitou-se, assim, de modo cada vez mais decidido e consciente, à representação, o mais convincente possível, do mundo empírico [...].

Para a burguesia emergente, a posse dos objetos artísticos constituía uma afirmação de poder. Nos palácios, os pintores e escultores eram tratados com familiaridade e relativa igualdade social e, paulatinamente, o caráter depreciativo conferido ao artesão responsável pela criação de pinturas e esculturas foi superado. Segundo Viadel (1997), pintura e escultura adquiriram o status de arte, ou seja, uma atividade criadora baseada em conhecimentos e regras racionais em contraposição aos ofícios manuais.

Além disso, o Renascimento consolidou a imitação como orientação para a criação artística, sendo que o ideal renascentista de mimese estava ligado à Antiguidade Clássica. Segundo Juan J. Jové Peres (1997), em Modos de Producción figural y educación artística, a redescoberta da cultura greco-romana contribuiu para que o perfeccionismo anatômico e os efeitos que provocavam a ilusão da realidade se tornassem os pilares da nova forma de criação visual desenvolvida à época.

Segundo Osinski (1998, p.27), houve uma ruptura entre a prática artística e sua aprendizagem. "A concepção humanista de cultura [...] fez com que o artista procurasse complementar sua habilidade manual com conhecimentos de natureza intelectual e cultural". Assim, a aproximação dos processos de criação artística com outras formas de conhecimento foi promovida, dentre outros fatores, pela contribuição teórica de artistas que relacionavam arte e ciência em suas obras, tais como Albrecht Dürer ${ }^{4}$, Lavinia Fontana ${ }^{5}$, Leon Battista Alberti ${ }^{6}$, Leonardo da Vinci ${ }^{7}$, Piero Della Francesca ${ }^{8}$ e Sofonisba Anguissola?.

Segundo Viadel (1997), nesse contexto, os conteúdos teóricos foram tidos como fundamentais para o ensino das artes e reforçaram a distinção entre a produção artística e o trabalho artesanal. Era necessário, portanto, uma instituição responsável para o ensino das artes. A criação da academia de desenho, em Florença, Itália, foi um marco para consolidação dessa concepção. O sistema desenvolvido pelas academias italianas no século XVI e pelas francesas no XVII foi tomado como referência por outras academias de belas artes na Europa e na América desde o século XVIII até começo do século XX, sendo, para Ana Mae Barbosa (2006), em Arte-Educação no Brasil, a célula mater do ensino de arte no Brasil.

Segundo Peres (1997) a metodologia das academias de belas artes se amparou em dois eixos: por um lado, na formação teórica baseada em estudos sobre: "[...] mundo clássico, mitologia, história, história e teoria da arte, geometria, teoria da

\footnotetext{
${ }^{4}$ Albrecht Dürer (1471 - 1528), gravador, pintor, ilustrador, matemático e teórico de arte alemão.

5 Lavinia Fontana (1552 - 1614), pintora italiana.

6 Leon Battista Alberti (1404 - 1472), arquiteto, teórico de arte e humanista italiano.

7 Leonardo di Ser Piero da Vinci, conhecido como Leonardo da Vinci (1452 - 1519), polímata e pintor italiano.

8 Piero Della Francesca (1416 - 1492), pintor italiano.

9 Sofonisba Anguissola (1532 - 1625), pintora renascentista italiana.
} 
perspectiva, teoria das proporções, anatomia e análise de obras" (PERES, 1997, p.302, tradução nossa), e por outro, na formação prática centrada especialmente na cópia em desenho.

No contexto do ensino de arte na educação escolar brasileira, a imitação, como procedimento principal de ensino, pode ser associada à chamada pedagogia tradicional. Conforme Demerval Saviani (2008), em Escola e democracia, essa proposta educativa foi estabelecida no país em meados do século XIX, com o propósito de difundir a instrução e transmitir conhecimentos sistematizados logicamente em uma perspectiva de progresso social e de consolidação dos valores burgueses.

De acordo com Ferraz e Fusari (2010), o desenvolvimento das aulas ocorria em uma sequência baseada na filosofia de Johan Friedrich Herbart (1776 - 1841). A metodologia consistia nas seguintes etapas:

a) recordação da aula anterior ou preparação para a aula do momento; b) apresentação de novos conhecimentos, principalmente através de aulas expositivas; c) assimilação do novo conhecimento por parte do aluno, por meio de comparações; d) generalização e identificação dos conhecimentos por meio de exercícios; e) aplicação dos novos conhecimentos em diferentes situações, atribuindo-se, para isso, "lições de casa" com exercícios de fixação e memorização (FERRAZ e FUSARI, 2010, p.25).

Esses procedimentos foram realizados para o ensino de diferentes áreas do conhecimento. No caso das artes visuais, predominaram ações com desenho a partir de exercícios de cópia realizados mediante controle rígido do professor, quem valorizava o resultado fidedigno. Na acepção de Vera Lúcia Penzo Fernandes (2004, p. 161), em A imitação no processo de aprendizagem: reflexões a partir da história da educação e do ensino arte, os métodos empregados no ensino por meio da mimese consolidaram um modelo de aprendizagem obtido "[...] em um processo dolorido e mecânico", fazendo com que, na prática, a mimese fosse associada às reproduções e cópias sem sentido, realizadas como um fim em si mesmo.

A crítica à pedagogia tradicional foi realizada prioritariamente por um movimento conhecido como escola nova que, segundo Fernandes (2010, p.48), "[...] apontou para a centralidade dos aspectos espontâneos da expressão e o desenvolvimento natural da criança [...]". Mas antes disso, no campo da produção artística, o ensino das academias já havia sido questionado por uma concepção de artista como sujeito que não imita a realidade exterior, mas que por meio de suas obras expressa seu mundo interior. Tratamos disso a seguir.

\section{O paradigma da autoexpressão: a criação como expressão do interior}

No contexto da produção artística, o modelo da mimese promovido pelas academias foi contraposto pelas reflexões propostas pelos artistas românticos. Combatendo os métodos de representação ensinados naquelas instituições, "[...] 
os românticos defendiam a valorização dos sentimentos e da disposição pessoal na criação da obra artística [...]" (OSINSKI, 1998, p.43).

Românticos, como o artista espanhol Francisco de Goya ${ }^{10}$, propunham a liberdade e originalidade como os princípios fundamentais para a criação. "A tese básica e distintiva que sustenta este modelo é que na arte não há regras, normas ou conceitos básicos gerais, nem, por extensão, nenhuma sequência estrita de aprendizagem" (VIADEL, 1997, p.68, tradução nossa).

Os adeptos desse movimento negavam a possibilidade de orientar o ensino de arte, pois priorizavam a ideia de que cada indivíduo deveria criar uma forma individual de trabalho, que enfatizasse sua personalidade e emoções individuais. Preconizando a relação direta com a natureza, os românticos viam na pintura ao ar livre um dos principais meios para inspiração e criação artística, segundo Osinski (1998).

Esse modelo é, nas palavras de Viadel (1997), uma espécie de antimodelo, pois, conforme explicou o autor, a perspectiva da autoexpressão estabelece que não é possível e nem desejável delimitar critérios rígidos e etapas progressivas para a criação artística, e propõe que, para criar, é necessário, basicamente, lançar-se à criação.

Essa posição foi consolidada no século XX por meio da produção de Allan Kaprow $^{11}$, Jean Dubuffet ${ }^{12}$, Joseph Beuys ${ }^{13}$, Marcel Duchamp ${ }^{14}$ e Meret Oppenheim ${ }^{15}$ . Esses artistas criaram um conjunto de situações que proporcionaram a dissolução do território das artes e da própria concepção sobre ser artista, condição que se reapresenta em diferentes trabalhos da arte contemporânea, conforme expôs Anne Cauquelin(2005) em Teorias da Arte.

No âmbito da educação escolar, segundo Osinski (2001), as pesquisas sobre o desenvolvimento das crianças "[...] fizeram com que as posições a respeito da manifestação artística infantil fossem reavaliadas" (OSINSKI, 2001, p. 59). Para a autora, o aparente descompasso entre as descobertas científicas e o ensino tradicional vigente provocou discussões acerca da necessidade de uma educação criadora, oposta ao sistema unilateral de "[...] transmissão de conhecimentos e à sua recepção mecânica pelos alunos, característico da escola tradicional" (OSINSKI, 2001, p. 59).

Conforme mencionamos anteriormente, as críticas feitas à abordagem tradicional levaram, em meados do século XIX, à constituição de uma nova tendência identificada como pedagogia nova ou escola nova. Em contraposição à tendência anterior, a escola nova deslocou, segundo avaliação de Saviani (2008, p.8):

[...] o eixo da questão pedagógica do intelecto para o sentimento; do aspecto lógico para o psicológico; dos conteúdos cognitivos para os métodos ou processos pedagógicos; do professor para o aluno; do esforço

\footnotetext{
10 Francisco José de Goya y Lucientes, conhecido como Francisco Goya (1746 - 1828), pintor e gravador espanhol.

11 Allan Kaprow (1927 - 2006), artista estadunidense.

12 Jean Philippe Arthur Dubuffet, conhecido como Jean Dubuffet (1901 - 1985), pintor francês.

13 Joseph Heinrich Beuys, conhecido como Joseph Beuys (1921 - 1986), artista alemão.

14 Marcel Duchamp (1887 - 1968), artista francês.

15 Meret Oppenheim (1913-1985), artista plástica e fotógrafa suíça.
} 
para o interesse; da disciplina para a espontaneidade; do diretivismo para o não diretivismo; da quantidade para a qualidade; de uma pedagogia de inspiração filosófica centrada na ciência da lógica para uma pedagogia de inspiração experimental baseada principalmente nas contribuições da biologia e da psicologia. Em suma, trata-se de uma teoria pedagógica que considera que o importante não é aprender, mas aprender a aprender.

A promoção da ação espontânea das crianças legitimou, em alguns contextos, a visão romântica de criação como uma vocação inata. A orientação metodológica fundamental nessa perspectiva consistia em proporcionar ambientes que possibilitassem às crianças "liberdade" para criar. Conforme relatou Peres (1997, p.333, tradução nossa) ao analisar essa tendência, dois princípios guiavam o trabalho educativo: "deixar que a criança se expresse livremente e renunciar a qualquer tipo de intervenção externa que pudesse contaminar seu ilimitado e virginal potencial". Nessa direção, nas palavras de Saviani (2008, p.8), caberia ao professor agir "[...] como um estimulador e orientador da aprendizagem cuja iniciativa principal caberia aos próprios alunos".

Fusari e Ferraz (2010, p.30) descreveram a ordenação metodológica realizada em nome dessa tendência:

a) começar uma atividade b) que suscitasse um determinado problema e c) provocasse o levantamento de dados a partir dos quais d) se formulassem hipóteses explicativas do problema e se desenvolvesse a experimentação, realizada conjuntamente por alunos e professor, para confirmar ou rejeitar as hipóteses formuladas.

Frente a isso, conforme explicou Fernandes (2007) no texto Uma leitura sóciohistórica da imitação no processo de ensino e aprendizagem, essa concepção proporcionou uma compreensão restrita sobre o processo de imitação, que passou a ser concebido de maneira negativa no ensino de arte. Há, ainda hoje, o entendimento de que a cópia "[...] restringe a criatividade e neutraliza a livre expressão dos alunos" (FERNANDES, 2007, p.1), ou ainda, há a negação da utilização de referências para o ensino de artes visuais em função dos "[...] danos que podem causar ao potencial criador e a padronização dos desenhos infantis" (FERNANDES, 2004, p. 158).

Com esse conjunto de argumentos destacamos que as metodologias para o ensino de arte embasadas nos paradigmas da mimese e da autoexpressão revelam concepções divergentes sobre a relevância da atividade reprodutora no ensino e os métodos para o desenvolvimento da criação artística. A seguir, analisamos essas abordagens.

\section{Superando dicotomias: o ensino de arte e a relação dialética entre reprodução e criação}


Mediante à apresentação de aspectos históricos que mobilizaram o desenvolvimento dos paradigmas da mimese e da autoexpressão, demonstramos que ambos denotam conceitos e encaminhamentos metodológicos divergentes para o desenvolvimento dos processos de criação artística e para o ensino de arte. Conforme avaliou Maria Claudia da Silva Saccomani (2016) em A criatividade na arte e na educação escolar, as ideias vinculadas a essas concepções, ainda hoje, podem ser reconhecidas em discursos pedagógicos que sustentam dualismos como: reprodução versus criação; transmissão versus construção; e ensino orientado versus aprendizagem espontânea.

Nessa direção, para Fernandes (2004, p. 167), o ecletismo ou a ausência de compreensão sobre os princípios teóricos que orientam cada tendência, faz com que as ações para o ensino de arte deem "[...] ênfase à livre-expressão, de acordo com os princípios escolanovistas, ou a uma mera reprodução de modelos, mesmo que os estejam negando".

Para avaliar os limites e potencialidades dos dois paradigmas, consideramos necessário superar uma análise dualista entre as abordagens, própria à lógica formal ${ }^{16}$ e, para tanto, buscamos compreender as relações entre criação e reprodução em uma lógica dialética ${ }^{17}$. As pesquisas de Lev Semionovitch Vigotski ${ }^{18}$ (1896 - 1934) sobre o papel da imitação para o desenvolvimento humano (VYGOTSKY, 2001; 2003; 2006) e sobre a criação na infância (VIGOTSKI, 2018) nos auxiliaram a compreender a relação dialética entre reprodução e criação nas artes visuais.

O autor se dedicou ao problema da imitação quando tratou sobre o método de investigação clínica para diagnóstico do desenvolvimento intelectual de crianças utilizado em seu tempo. Conforme explicou, as avaliações eram realizadas mediante a aplicação de testes baseados nas respostas que as crianças poderiam apresentar sozinhas, isto é, sem interferência de um examinador. Conforme explicou em Historia del desarrollo de las funciones psíquicas superiores (VYGOTSKY, 2003), predominava a concepção de que a exposição de exemplos que pudessem ser imitados pelas crianças e que as auxiliassem na resolução da tarefa apresentada pelos investigadores consistia na "[...] transferência mecânica de uma forma de conduta já elaborada à outra" (VYGOTSKY, 2003, p.136, tradução nossa) e, portanto, essa mesma exposição era dispensada nos exames clínicos para avaliação do desenvolvimento intelectual infantil. Contrário a esse procedimento, o autor criticou, em Psicología infantil (VYGOTSKY, 2006, p.267, tradução nossa), a concepção de que "[...] toda imitação de

\footnotetext{
16 Conforme Duarte (2016, p. 204-205) "a lógica formal trabalha com a mútua exclusão entre o princípio da identidade e princípio da não identidade. Nessa perspectiva, tudo que existe é igual a si mesmo, é a afirmação de si mesmo, não admitindo sua negação, não sendo possível, portanto, que A seja $A$ e ao mesmo tempo seja B, que é distinto de $A^{\prime \prime}$.

17 "[...] a lógica dialética não considera que os princípios da identidade e da não identidade sejam excludentes. Uma coisa é idêntica a ela mesma, mas como a realidade está em permanente movimento, as contradições internas que produzem esse movimento, fazem com que uma coisa possa ser ela mesma e, ao mesmo, algo diferente." (DUARTE, 2016, p. 204-205)

18 Em relação à grafia do nome do autor, utilizamos a forma Lev Semionovitch Vigotski (Лев Семёнович Выго́тский) ao longo de todo o texto. Nas referências, contudo, mantivemos as formas de transliteração utilizadas pelos tradutores da bibliografia consultada.
} 
uma operação intelectual pode ser um ato puramente mecânico e automático, e que nada demonstra sobre a inteligência do sujeito". Ao contrário, entendia que "[...] os processos de imitação são muito mais complexos do que parecem à primeira vista" (VYGOTSKY, 2003, p.136-137, tradução nossa).

Vigotski demonstrou que, sem auxílio, as crianças conseguiam realizar tarefas limitadas pelo "[...] grau de seu desenvolvimento mental e pelas possibilidades que correspondem à sua idade" (VYGOTSKY, 2006, p.267-268, tradução nossa), porém, com auxílio de modelos que contribuíam para a resolução da tarefa, as mesmas crianças eram capazes de imitar ações intelectuais para além dessas limitações. Nesse sentido, a imitação, segundo o autor, não se refere a uma ação mecânica e automática, mas a uma ação "[...] racional, baseada na compreensão da operação intelectual que se imita" (VYGOTSKY, 2006, p.268, tradução nossa).

Com base nisso consideramos que o conceito de mimese não se restringe àquele próprio da escolarização tradicional, isto é, da reprodução como um fim em si mesmo. Conforme explicou Fernandes (2007, p.3), Vigotski "[...] vê na imitação um processo dinâmico que favorece e possibilita a aprendizagem, desmistificando o aspecto mecânico ou restrito que the é conferido". A autora constatou que a imitação pode contribuir para a aprendizagem em arte quando observou aulas realizadas em escolas públicas de Ensino Fundamental. Relatou que as professoras faziam desenhos no quadro e, à medida que traçavam, orientavam os alunos sobre o significado de cada linha. Eles, por sua vez, "[...] olhavam para o que a professora estava desenhando e copiavam em seus cadernos [...]" e "[...] ao mesmo tempo em que a professora desenhava, complementando o desenho, os alunos também desenhavam" (FERNANDES, 2010, p. 52). Embora essa ação pareça conduzir apenas a uma cópia do modelo apresentado, ao analisar o processo e os resultados da metodologia utilizada pela professora no contexto investigado, a autora concluiu que ela

[...] representa, na verdade, o seguinte desdobramento: no momento em que os alunos reproduzem os gestos da professora, estão desenvolvendo ações que thes permitiram compreender as técnicas de representação, acompanhando os passos e imitando os gestos da professora, apropriandose dos mecanismos por ela utilizados para apropriarem-se do conceito estudado. Porém, cada aluno apresenta traços próprios, reproduzem e criam ao mesmo tempo (FERNANDES, 2010, p. 52).

A singularidade apresentada pelo desenho dos alunos do caso relatado resulta da vivência de cada sujeito naquele momento e, ao mesmo tempo, de suas experiências anteriores. Assim, a expressão das crianças não decorre de um potencial natural, como fazem crer argumentos românticos relacionados ao paradigma da autoexpressão, mas é resultado do conjunto de referências culturais vivenciadas por elas. Sua gênese e seu caráter não são naturais, mas sim, sociais. Conforme expressou Vigotski (2018, p.22), em Imaginação e Criação na Infância "[...] toda obra da imaginação constróise sempre de elementos tomados da realidade e presentes na experiência anterior da pessoa". Portanto, consideramos que as referências culturais estão presentes em todas as ações humanas e, por conseguinte, não cabe contrapô-las aos processos 
de criação. Essas referências expressam os limites da experiência de cada indivíduo, e o reconhecimento desses limites potencializa a ação criadora. Como salientou a artista e pesquisadora Fayga Ostrower (2001, p.160, grifo da autora), em Criatividade e processos de criação: "[...] a própria aceitação de limites [...] é o que nos propõe o real sentido da liberdade no criar".

\section{Considerações finais}

Neste texto analisamos as concepções sobre os processos de criação vinculados a dois paradigmas teórico-metodológicos consolidados para o ensino de artes visuais (o da mimese e o da autoexpressão). Mostramos, recuperando aspectos históricos e metodológicos, que, segundo o paradigma da mimese, criar consiste em reproduzir. Nos espaços escolares, a reprodução acabou sendo realizada como um fim em si mesmo, por meio de exercícios de cópia com pouco significado. Em resposta a essa concepção, o paradigma da autoexpressão nega a necessidade de referências externas para o processo criativo, propondo a busca e revelação de imagens internas pelo sujeito criador. Criar, nesse caso, consiste em expressar seu interior, resultado da natureza de cada indivíduo.

Para superar a visão dicotômica promovida pelos paradigmas, analisamos as duas concepções em uma lógica que possibilitou ampliar o conceito de cópia associado ao paradigma da mimese, assim como identificar o limite da proposta de autoexpressão. Como argumentamos, há uma relação entre imitação e desenvolvimento intelectual, de modo que imitar, como um meio para a apropriação de conhecimentos, não se resume a uma ação mecânica, automática e sem sentido (como por vezes ocorre nas propostas educativas baseada na mimese), mas indica possibilidades de ensino, aprendizagem e desenvolvimento. Nessa lógica, a expressão de cada pessoa (ao contrário do proposto pela perspectiva da autoexpressão) está diretamente relacionada às experiências anteriormente vivenciadas por elas e às referências que estiveram à sua disposição e, por conseguinte, não decorre de fatores inatos, mas sim sociais.

Com isso, entendemos que desenvolver processos de criação em artes visuais na Educação Básica implica possibilitar a apropriação de conhecimentos e habilidades desenvolvidos historicamente, pois a reprodução, no âmbito individual, daquilo que fora criado e é compartilhado socialmente, representa a formação da base que possibilitará o desenvolvimento de novas criações. Assim, consideramos adequado, que exemplos das produções artísticas sejam expostos, vistos, discutidos, analisados, contextualizados e imitados para que eles possam servir como referência para a atividade criadora nos espaços de Educação Básica. 


\section{Referências}

BARBOSA, Ana Mae. Arte-Educação no Brasil. São Paulo: Perspectiva, 2006.

BRASIL. Lei de Diretrizes e Bases da Educação Nacional. Lei n. 9.394 de 20 de dezembro de 1996. Disponível em: < http://www.planalto.gov.br/ccivil_03/leis/19394.htm>. Acesso em: 31 de março de 2020.

CAMARGO, Marcos Henrique. As estéticas e suas definições da arte. Revista Científica/ FAP, [S.I.], jun., p.1-15, 2009. Disponível em: http://periodicos.unespar.edu.br/index.php/ revistacientifica/article/view/1593. Acesso em: 31 de março de 2020.

CAUQUELIN, Anne. Teorias da Arte. Tradução: Rejane Janowitzer. São Paulo: Martins Fontes. 2005.

DIRETÓRIO DOS GRUPOS DE PESQUISA NO BRASIL. Grupo de Pesquisa e Estudos em Educação Infantil. 2020. Disponível em:dgp.cnpq.br/dgp/espelhogrupo/8433138424054924, acesso em 01 de junho de 2020.

DUARTE, Newton. Prefácio. In: SACCOMANI, Maria Claudia da Silva. A criatividade na arte e na educação escolar: uma contribuição à pedagogia histórico-crítica à luz de Georg Lukács e Lev Vigotski. Campinas, São Paulo. Autores Associados, 2016. (Educação contemporânea).

FERNANDES, Vera Lúcia Penzo. A imitação no processo de aprendizagem: reflexões a partir da história da educação e do ensino arte. Série-Estudos (UCDB), Campo Grande, v. 17, n.17, p.157-170, 2004. Disponível em: http://www.serie-estudos.ucdb.br/index.php/serie-estudos/ article/view/499. Acesso em: 31 de março de 2020.

. A imitação no processo de ensino e aprendizagem de arte. OuvirOUver (Uberlândia. Impresso), v. 6, p.46-61, 2010. Disponível em: http://www.seer.ufu.br/index.php/ouvirouver/ article/view/8221.Acesso em: 31 de março de 2020.

Uma leitura sócio-histórica da imitação no processo de ensino e aprendizagem. In: 30a Reunião Anual da Associação Nacional de Pesquisa e Pós-graduação em Educação, 2007, Caxambu. ANAIS da 30ª Reunião Anual da Associação Nacional de Pós-graduação e Pesquisa em Educação, 2007.

FERRAZ, Maria Heloísa Corrêa de Toledo; FUSARI, Maria Felisminda de Rezende. Arte na educação escolar. 4. ed. São Paulo: Cortez, 2010.

GIL, Antonio Carlos. Como elaborar projetos de pesquisa. São Paulo: Atlas, 2002.

HAUSER, Arnold. História social da arte e da literatura. Trad. A. Cabral. São Paulo: Martins Fontes, 1994.

KANDINSKY, Wassily. Do espiritual na arte e na pintura em particular. Tradução: Álvaro Cabral e Antonio de Pádua Danesi. São Paulo: Martins Fontes, 1996.

OSINSKI, Dulce Regina Baggio. Ensino da Arte: os Pioneiros e a influência estrangeira na 
arte-educação em Curitiba. 327 f. Dissertação. Mestrado em Educação. Universidade Federal do Paraná, UFPR, Brasil. Orientadora: Maria Cecília Marins de Oliveira. 1998.

Arte, história e ensino: uma trajetória. São Paulo: Cortez, 2001.

OSTROWER, Fayga. Criatividade e processos de criação. 15 ed. Petrópolis, RJ: Vozes, 2001.

PERES, Juan J. Jové. Modos de Producción figural y educación artística: Los primeros pasos de un modelo didáctico. Tesis Doctoral. Orientador: Jaume Sanuy Burgués. Departamento de Pedagogía y Psicología de la Universidad de Lleida. Espanha. 1997.

SACCOMANI, Maria Claudia da Silva. A criatividade na arte e na educação escolar: uma contribuição à pedagogia histórico-crítica à luz de Georg Lukács e Lev Vigotski. Campinas, São Paulo. Autores Associados, 2016. (Educação contemporânea).

SANTAELLA, Lucia. Porque as comunicações e as artes estão convergindo? São Paulo: Paulus, 2005.

SAVIANI, Demerval. Escola e democracia. Campinas, SP: Autores Associados, 2008. (Coleção educação contemporânea). "Edição comemorativa".

Trabalho e educação: fundamentos ontológicos e históricos. Rev. Bras. Educ., Rio de Janeiro, v. 12, n. 34, p.152-165, Abr. 2007. Disponível em: www.scielo.br/pdf/rbedu/v12n34/ a12v1234.pdf. Acesso em: 31 de março de 2020.

STEIN, Vinícius. Formação artística e estética de professores e crianças: Desenvolvimento da criação com artes visuais na Educação Infantil. 140f. Tese (Doutorado em Educação) Universidade Estadual de Maringá. Orientadora: Dra. Marta Chaves. Maringá, 2019.

VIADEL, Ricardo Marín. Enseñanza y aprendizaje en Bellas Artes: una revisión de los cuatro modelos históricos desde la perspectiva contemporánea. Arte, Individuo y Sociedad, Madrid, n. 9, p. 55-77. Servicio de Publicaciones. Universidad Complutense. 1997. Disponível em: https://revistas.ucm.es/index.php/ARIS/article/view/ARIS9797110055A. Acesso em: 31 de março de 2020.

VIGOTSKI, Lev Semionovitch. Imaginação e criação na infância: ensaio psicológico. Tradução de Zoia Prestes e Elizabeth Tunes. 1. Ed. São Paulo: Expressão Popular, 2018.

VYGOTSKY, L. S. Historia del desarrollo de las funciones psíquicas superiores. In:

Obras Escogidas. Tomo III. Problemas del desarollo de la psique. Tradução: Lydia Kuper. 2.ed. Madrid: Visor Dis., 2003.

Obras Escogidas. Tomo IV. Psicología infantil. Tradução: Lydia Kuper. 2.ed. Madrid: A. Machado Libros, 2006.

Pensamiento y lenguaje. In: Obras Escogidas. Tomo II. Problemas Psicología general. Tradução: José Maria Bravo. 2.ed. Madrid: A. Machado Libros, 2001.

Recebido em 02 de abril de 2020. Aprovado em 15 de junho de 2020. 